\title{
THE EFFECT OF ORAL HEALTH EDUCATION SEMINAR ONTHE ORAL HEALTH KNOWLEDGE, PRACTICE AND PERCEPTION OF ROLE OF THE PRESCHOOL TEACHERS
}

N.A. Mohd Nor, S. Zakaria, N.H. Amminudin, A.M. Mohd Khairi, N.A. Malik. The effect of oral health education seminar on the oral health knowledge, practice and perception of role of the preschool teachers. Annal Dent Univ Malaya 2013; 20(2): 4-8

\begin{abstract}
Background: In Malaysia, preschool teachers have long been utilised as oral health educators. However their level of oral health knowledge and effectiveness of the training they received are seldom investigated. This study aims to evaluate the of oral health education seminar (OHE) held for public preschool teachers (KEMAS) in terms of the improvement of their knowledge, practices and attitudes Methods: This was a one arm interventional study (before and after survey following OHE seminar intervention). All KEMAS preschool teachers $(n=107)$ in Hulu Terengganu were invited to attend OHE seminar which consisted of 1 hour lecture and 40 minutes OHE demonstration. Pretest questionnaire was collected before the seminar started and post-test questionnaire was collected two weeks later. A self-administered questionnaire used in this study was adapted from "preschool teachers' knowledge, practices and attitudes towards oral health", National Oral Health Survey of Preschool Children, 2005. Data were analysed using descriptive and McNemar test, SPSS version 15.0. Results: Of 107 subjects, only 61 teachers responded yielding to $57 \%$ response rate. All subjects were female with mean age of 46 years (SD: 6.03). Overall, there was an improvement of teachers' oral health knowledge, practices and attitudes after the seminar. Several items seem to have be improved significantly after the seminar, for example knowledge item on factors causing periodontal disease $(p=0.03)$. In terms of practice, all teachers reported they brushed teeth at least twice daily using fluoridated toothpaste and use of dental floss was increased significantly after the seminar $(p<0.001)$. Majority of teachers have positive perceptions on their roles in oral health education. Conclusion: Oral health education seminar appeared to be effective at influencing certain aspects of teachers' oral health knowledge, practices and attitudes.
\end{abstract}

Keywords: attitudes, knowledge, oral health promotion, practice, preschool teachers.
Original Article

N.A. Mohd Nor ${ }^{1}$, S. Zakaria ${ }^{2}$, N.H. Amminudin ${ }^{2}$,
A.M. Mohd Khairi ${ }^{3}$, N.A. Malik ${ }^{2}$
'Department of Community Oral Health and
ClinicalPrevention, FacultyofDentistry, University
Malaya, Kuala Lumpur.
${ }^{2}$ Oral Health Division, Terengganu State Health
Department, Ministry of Health Malaysia.
'University Malaysia Terengganu, Kuala
Terengganu, Terengganu.
Corresponding Author:
Dr. Nor Azlida Mohd Nor
Email: azlida@um.edu.my

\section{INTRODUCTION}

A multi-disciplinary approach is needed for effective dental education for children. Teachers are identified as key alternative personnel to be involved in combating preventable diseases such as oral disease $(1,2)$. There is a vast body of evidence acknowledging the advantages of utilising the services' of teachers in school health education and health promotion. Teachers are able to influence a huge number of children, parents and members of the community (1-5). Due to the fact that teachers spend a great deal of time with their students daily, they can ensure that oral health message is delivered to children continuously. They will also be able to incorporate oral health message into the school's general health curriculum $(2,3,6)$.

Apart from the potential advantages of utilising teachers in oral health education, the main weakness reported was teachers' lack of training in delivering health messages $(2,6,7)$. Other barriers reported were lack of materials (4), insufficient time and failure to incorporate oral health into the curriculum (3). These barriers may prevent teachers from effectively participating in oral health promotional activities.

A structured preschool oral health programme has been implemented in Malaysia since 1984 focusing on preventive and promotional activities in oral health (8) which includes yearly clinical visits to kindergartens by dental nurses. Preschool teachers have long been utilised as oral health educators for this programme. 
In spite of having had a comprehensive preschool oral health programme for nearly three decades, dental caries among preschool children remains a significant dental public health problem in Malaysia, particularly in rural communities (9). The National Oral Health Survey of Preschool Children, 2005 reported that five year old preschool children in Terengganu have the second highest caries prevalence $(95.5 \%)$ and caries experience $(\mathrm{dft}=9.6)$ in Malaysia (10). Within the state, Hulu Terengganu has the second lowest of caries free mouths among 6 years old children (11). The alarming numbers of poor oral health status among preschool children in Terengganu has resulted in a call by the state to strengthen its oral health promotion programme. One of the measures taken was to evaluate the yearly oral health education seminar, for preschool teachers in rural areas. The result of this evaluation plays a vital role for the improvement of such interventions (12). Thus, this study was conducted to evaluate the effectiveness of the oral health education seminar held for preschool teachers in Hulu Terengganu, for the improvement of their oral health knowledge, attitudes and practices.

\section{METHODS}

This study was a one arm intervention study (before and after survey following oral health education seminar intervention). A pre and post seminar survey was conducted using a self-administered questionnaire involving all public preschool teachers $(\mathrm{n}=107)$ in "Jabatan Kemajuan Masyarakat" (KEMAS), Ministry of Rural and Regional Development, in the district of Hulu Terengganu. KEMAS preschool teachers were chosen because dental services to these kindergartens are fully covered by the Terengganu State Dental Division.

A questionnaire was adapted from the National Oral Health Survey of Preschool Children, 2005 (10). The questionnaire consisted of four sections. Section A was to gain demographic information which includes age, gender and education level. Section B comprised of six questions on oral health knowledge including knowledge on plaque, factors causing caries, signs of periodontal disease, factors causing periodontal disease, prevention of caries and prevention of periodontal disease. Section C comprised of four questions on perceived oral health care practices including tooth brushing habits, usage of fluoridated toothpaste and flossing habits. Section D comprised of five questions on the perceived roles of teachers towards oral health education. For section B and C, response formats was multiple choice answers in which subjects choose one or more correct answer from the provided list of answer options. For section D, respondents were asked to indicate the extent of their agreement or disagreement on perceptions of roles of teachers in oral health education.
A five point Likert scales ranging from strongly agree to strongly disagree was used (10).

The questionnaire was face validated by two dental public health specialists in Oral Health Division, Ministry of Health, Malaysia. They were asked to provide feedback independently on the overall content and structure of the questionnaire. The feedback received from the experts only involved minor structural adjustments. The questionnaire was pre-tested among five KEMAS preschool teachers in other districts. Following the pre-test, the questionnaire was found to be clear and relevant with no changes required.

All participants were invited to attend oral health education seminar which consisted of 1 hour lecture and 40 minutes of oral health education demonstration. The lecture-demonstration method of oral health education used was almost similar to those used in other studies $(12,13)$. Pre-test questionnaires were distributed just before the seminar and collected on the same day. The module of the oral health education seminar was based on "Guidelines of Oral Healthcare for Preschool Children" (8). The lecture was given by a dental public health specialist and oral health education demonstration was done by two calibrated dental officers. Oral health education demonstration was divided into two stations. Each interactive 20-minutes station utilized audio-visual aids (models, pictures, posters and flip charts). The first station focused on common oral disease (which includes normal structure and functions of teeth, type of dentitions and their significance, aetiology of dental caries and periodontal disease, clinical manifestations and treatment modalities). The second station focused on basic oral health care (which includes prevention of dental caries, periodontal disease, effective tooth brushing technique, flossing, importance of regular dental visits, the importance of having a balanced diet and influence of oral health on general health). Teachers were divided into small groups (consisting of 15 people maximum) for rotational demo station. For post-test the same structured questionnaires were distributed to all teachers and collected two weeks after the pre-test. The reason of having the two weeks intervals of pre-test and post-test were meant to provide adequate period of knowledge/behavioural change after the intervention and at the same time minimize the contamination effects from other influences or factors that can contribute to the observed changes (9). For statistical analysis purposes, both pre and post-tests questionnaires were anonymous and identification code numbers were used to match mentioned questionnaires.

Ethical approval to conduct this study was obtained from Medical Ethics Committee, University of Malaya. Permission to conduct this study was obtained from the Terengganu State Dental Division and "Jabatan Kemajuan Masyarakat" (KEMAS), Ministry of Rural and Regional Development. Following approval, a letter was sent to invite all KEMAS preschool teachers in Hulu Terengganu 
to participate in this study. Participants were assured of confidentiality.

\section{Data management and analysis}

Data were analysed using SPSS version 15.0 and significant value was set at 0.05 . For oral health knowledge section, the answers were grouped as "true" and "false" answer and for oral hygiene practice section, the answers were grouped as "yes" and "no" answer. In terms of the perception scores, the answers were grouped into "agree" and "disagree" to indicate level of acceptance of roles of preschool teachers towards oral health education. Descriptive and McNemar test was used to analyse the percentage improvement between before and after intervention.

\section{RESULTS}

All public preschool teachers of KEMAS Hulu Terengganu $(n=107)$ were invited to participate in this study. Sixty one teachers responded, giving a response rate of $57 \%$. Of the 61 participants, two participants were absent during posttest and data was excluded from analysis. All participants were female with mean age of 46 years (SD: 6.03). In terms of education level, majority $(80.0 \%)$ completed secondary school level education, followed by $13.3 \%$ having completed tertiary education and $6.7 \%$ having completed primary school education.

\section{Oral health knowledge}

Table 1 indicates some improvement of oral health knowledge percentage after oral health education seminar

Table 1: Distribution of percentage oral health knowledge before and after oral health education seminar among preschool teachers in Hulu Terengganu $(n=59)$

\begin{tabular}{lccc}
\hline & \multicolumn{2}{c}{ Correct answer } & \\
& $\begin{array}{c}\text { Pre-test } \\
\mathrm{n}(\%)\end{array}$ & $\begin{array}{c}\text { Post-test } \\
\mathrm{n}(\%)\end{array}$ & p-value* \\
\hline $\begin{array}{l}\text { B1. Knowledge on } \\
\text { plaque }\end{array}$ & $58(98.3)$ & $58(98.3)$ & 1.00 \\
$\begin{array}{l}\text { B2. Factors causing } \\
\text { caries }\end{array}$ & $22(37.3)$ & $23(39.0)$ & 1.00 \\
$\begin{array}{l}\text { B3. Signs of } \\
\text { periodontal disease }\end{array}$ & $12(20.3)$ & $14(23.7)$ & 0.75 \\
$\begin{array}{l}\text { B4. Factors causing } \\
\text { periodontal disease }\end{array}$ & $10(16.9)$ & $18(30.5)$ & $0.03^{*}$ \\
$\begin{array}{l}\text { B5. Prevention of } \\
\text { caries }\end{array}$ & $23(39.0)$ & $29(49.2)$ & 0.21 \\
$\begin{array}{l}\text { B6. Prevention of } \\
\text { periodontal disease }\end{array}$ & $12(20.3)$ & $13(22.0)$ & 1.00 \\
\hline
\end{tabular}

*McNemar test, significant at $\mathrm{p}<0.05$ intervention. Almost all teachers understand what dental plaque is before and after the intervention. Apart from having knowledge of plaque, overall findings reflect poor oral health knowledge among preschool teachers in Hulu Terengganu. Although the percentage of improvement is less than $20 \%$, there was a significant improvement of knowledge on factors causing periodontal disease $(p=0.03)$ after the seminar. However, there was no significant difference in relation to knowledge of signs of periodontal disease, prevention of periodontal disease, prevention of caries and factors causing caries $(\mathrm{p}>0.05)$.

\section{Oral hygiene practices}

Table 2 shows distribution of oral hygiene practices among preschool teachers in Hulu Terengganu. All respondents $(n=59)$ reported that they brushed at least twice daily using fluoridated toothpaste. The use of dental floss among the respondents improved significantly after the intervention $(\mathrm{p}<0.001)$.

\section{Perceptions of roles of teachers}

Generally, it was found that preschool teachers have positive perceptions on their roles in oral health education during pre-test ranging from $86.4 \%$ to $89.8 \%$. Of this, their role in recognizing tooth decay and gum problems in preschool children, supervising of daily tooth brushing during school hours, controlling of foods served, setting examples to children by having good oral health and the insertion of dental messages into lessons as often as possible (Table 3). There was no statistical significant difference found before and after the seminar for all items ( $p>0.05)$. However, after the seminar there was increased agreement percentage (over 90\%) to all questions on teachers' roles in oral health education in preschool setting.

Table 2: Distribution of percentage oral hygiene practices before and after oral health education seminar among preschool teachers in Hulu Terengganu $(n=59)$

\begin{tabular}{|c|c|c|c|}
\hline & \multicolumn{2}{|c|}{ Who answer Yes } & \multirow[b]{2}{*}{ p-value* } \\
\hline & $\begin{array}{l}\text { Pre-test } \\
\mathrm{n}(\%)\end{array}$ & $\begin{array}{l}\text { Post-test } \\
\mathrm{n}(\%)\end{array}$ & \\
\hline $\begin{array}{l}\text { C1. Tooth brushing } \\
\text { ( } \geq \text { once) }\end{array}$ & 59 (100) & 59 (100) & 0.18 \\
\hline $\begin{array}{l}\text { C2. Use of fluoridated } \\
\text { toothpaste }\end{array}$ & $59(100)$ & $59(100)$ & 1.00 \\
\hline C3. Use of dental floss & $15(25.4)$ & $35(59.3)$ & $<0.001^{*}$ \\
\hline
\end{tabular}

*McNemar test, significant at $\mathrm{p}<0.05$ 
Table 3: Distribution of percentage roles of teachers before and after oral health education seminar in a sample of preschool teachers in Hulu Terengganu $(n=59)$

\begin{tabular}{|c|c|c|c|}
\hline & \multicolumn{2}{|c|}{ Agree } & \multirow[b]{2}{*}{$p$-value* } \\
\hline & $\begin{array}{c}\text { Pre-test } \\
\mathrm{n}(\%)\end{array}$ & $\begin{array}{c}\text { Post-test } \\
\text { n (\%) }\end{array}$ & \\
\hline $\begin{array}{l}\text { D1. Able to recognize } \\
\text { tooth decay and gum } \\
\text { problems in children }\end{array}$ & $52(88.1)$ & $54(91.5)$ & 0.75 \\
\hline $\begin{array}{l}\text { D2. Supervise daily } \\
\text { tooth brushing of } \\
\text { children during school } \\
\text { hours }\end{array}$ & $51(86.4)$ & 55 (93.2) & 0.34 \\
\hline $\begin{array}{l}\text { D3. Control of foods } \\
\text { served to preschool } \\
\text { children }\end{array}$ & 53 (89.8) & 56 (94.9) & 0.45 \\
\hline $\begin{array}{l}\text { D4. Set an example } \\
\text { to children by having } \\
\text { good oral health }\end{array}$ & $52(88.1)$ & 55 (93.2) & 0.45 \\
\hline $\begin{array}{l}\text { D5. Include dental } \\
\text { message into lessons } \\
\text { as often as possible }\end{array}$ & $53(89.8)$ & 55 (93.2) & 0.69 \\
\hline
\end{tabular}

*McNemar test, significant at $\mathrm{p}<0.05$

\section{DISCUSSION}

Findings from this study indicated that there was increased level of knowledge among preschool teachers after attending the oral health education intervention seminar. However, it is worth noticing that, the percentage improvement is relatively very small (less than 20\%). The result of this study was consistent with another local study conducted among KEMAS preschool teachers in Kelantan (9). Despite of the percentage of improvement was no greater than $20 \%$, the overall outcome suggests that the oral health education seminar appeared to be effective at influencing certain aspects of teachers' oral health knowledge, practices and attitudes, hence empowering them as agents of change.

Although there was an improvement in oral health knowledge, overall findings reflect poor oral health knowledge among preschool teachers in Hulu Terengganu. Similar results were reported by other studies $(1,6)$, which suggest that teachers' knowledge about oral health and current methods of prevention are incomplete and inaccurate. The teachers' lack of oral health knowledge may affect what they convey to their pupils, as it is generally believed that an individual cannot give what he or she does not have (6). Providing in-service programmes for teachers such as oral health education seminars is one approach to raise oral health awareness (1). Teachers should be reminded of the reasons and benefits of such programmes. Findings from this study suggest the need to increase training on oral health education among preschool teachers to ensure accurate information delivery to their pupils. In addition, repeated reinforcement will help to increase knowledge and develop positive habits (6).

All preschool teachers in the present study were reported to have good oral hygiene practices before and after exposure to oral health education by brushing their teeth more than once daily using fluoridated toothpaste. This basic information might be influenced by annual preschool visits by dental nurses and sophisticated mass media in promoting oral health education (9). On a positive note, there was significant improvement $(p<0.001)$ reported in terms of flossing habits among respondents after the intervention from $25.4 \%$ (pre-test) to $59.3 \%$ (post-test). This post-test percentage was higher than the national average of flossing habits reported among Malaysian preschool teachers (39.9\%) (10).

There was conflicting findings in terms of teachers' perceptions of their roles in oral health education activities. Results from the present study indicated that teachers have positive perceptions towards their roles in oral health education which require their direct involvement and supervision during school time. This finding was supported by other studies in Trinidad (3) and India (14). In contrast, some teachers, though quite knowledgeable with respect to oral health, had poor levels of motivation and commitment related to oral health activities (7). Thus, the positive attitudes of teachers in the present study should be encouraged. The main challenge however, will be how to ensure proper implementation of the existing guidelines and to evaluate effectiveness of the oral health education of the children.

The response rate $(57 \%)$ for this study was relatively low compared to other studies among school teachers. This could be explained that the seminar was conducted during school holidays whereby many teachers were involved with continuous education programme to upgrade their qualification from certificate to diploma level (15). Therefore, it is important for oral health personnel to include teachers during oral health programme planning stage to ensure maximum coverage of teachers receiving oral health education training. In addition, due to geographic distance, lack of public transportation and challenging roads in Hulu Terengganu, some teachers faced difficulty in accessing the seminar centre. Thus, multicentre training is recommended in the future.

Findings from this study should be interpreted in the light of some limitations. Firstly, due to nature of self-reporting survey there could have been reporting bias. Secondly, the results can only provide an insight about preschool teachers surveyed in Hulu Terengganu and should not be generalised to all preschool teachers in Malaysia. Thirdly, we were unable to determine whether the seminar had an impact on actual behaviour. It is recommended that future research is done to evaluate whether the knowledge, attitude and practices of preschool 
children could improve with the upgrading of preschool teachers' knowledge on oral health. In addition to that, a long term follow-up to assess the improvement of teachers' oral health knowledge, attitudes and practices should also be conducted.

\section{REFERENCES}

1. Lang P, Woolfolk MW, Faja BW. Oral health knowledge and attitudes of elementary schoolteachers in Michigan. J Public Health Dent 1989;49(1):44-50.

2. Mwangosi IE, Nyandindi U, Matee M. Participation of primary school teachers in oral health education in Rungwe District, Tanzania. East Afr Med J 2001;78(12):662-5.

3. Ramroop V, Wright D, Naidu R. Dental health knowledge and attitudes of primary school teachers toward developing dental health education. West Indian Med J 2011;60(5):576-80.

4. Mwangosi IE, Mwakatobe KM, Astrom AN. Sources of oral health information and teaching materials for primary schoolteachers in Rungwe District, Tanzania. Int Dent J 2002;52(6):469-74.

5. Petersen PE, Peng B, Tai B, Bian Z, Fan M. Effect of a school-based oral health education programme in Wuhan City, Peoples Republic of China. Int Dent J 2004;54(1):33-41.

6. EhizeleA, Chiwuzie J, OfiliA. Oral health knowledge, attitude and practices among Nigerian primary school teachers. Int J Dent Hyg 2011;9(4):254-60.

7. Nyandindi U, Palin-Palokas T, Milen A, Robison $\mathrm{V}$, Kombe N, Mwakasagule S. Participation, willingness and abilities of school-teachers in oral health education in Tanzania. Community Dent Health 1994;11(2):101-4.
8. Oral Health Division Ministry of Health, Malaysia. Guidelines on oral health care for preschool children. 2003.

9. Seman K YH, Hamid AM, Ismal AR, Yusoff A. Evaluation of a training programme for non-health professionals as oral health educators. Malays J Med Sci 2008;15 (2):33-36.

10. Oral Health Division Ministry of Health, Malaysia. National Oral Health Survey for Preschool Children (NOHPS). 2005.

11. Oral Health Division, Terengganu State Health Division, Ministry of Health, Malaysia. Impact indicators of Oral Health Division, Terengganu. 2012.

12. Ajithkrishnan CG TK, Sudheer H, Abhishek S. Impact of oral health education on oral health of 12 and 15 year old schoolchildren of Vadodara city, Gujarat state. J Int Oral Health 2010;2 (3):15-20.

13. Shenoy RP, Sequeira PS. Effectiveness of a school dental education program in improving oral health knowledge and oral hygiene practices and status of 12- to 13-year-old school children. Indian J Dent Res 2010;21(2):253-9.

14. Chandrashekar BR, Suma S, Kiran K, Manjunath BC. The use of school teachers to promote oral hygiene in some secondary school students at Hyderabad, Andhra Pradesh, India: A short term prospective pilot study. J Family Community Med 2012;19(3):184-9.

15. Latib S. Pertingkat taraf guru KEMAS. Utusan Malaysia. 20 July 2012. 